\title{
Research on Industry-University-Research Collaborative Innovation in Big Data Industry
}

\author{
Zhao Wang \\ Big Data Research Center \\ Jianghan University \\ Wuhan, China
}

\author{
Mengjie Wang \\ Big Data Research Center \\ Jianghan University \\ Wuhan, China
}

\author{
Wenqiang Bao* \\ YiBen Investment Fund \\ New York, United States
}

\begin{abstract}
The 19th National Congress report emphasizes that the deep integration of the Internet, big data, artificial intelligence and the real economy needs to be promoted further. The powerful combination of big data and industrial synergy innovation has become an important measure to enhance China's scientific and technological innovation strength. The main entities of collaborative innovation of industry-university-research in big data industry are enterprises, universities, research institutes and intermediary service agencies. The purpose of this paper is to clarify the division of responsibilities and innovative cooperation models of various entities. In this way, the collaborative innovation and development of industry-university-research in big data industry could be realized and the continuous innovation of big data technology in China could be promoted.
\end{abstract}

Keywords - big data industry; industry-university-research; collaborative innovation; cooperation model

\section{INTRODUCTION}

According to China's big data application industry report, the marketing scale of China's big data market reached RMB 25.86 billion in 2018 , with a growth rate of $37.2 \%$. It shows that China's big data industry is entering a period of rapid development. However, the penetration power of big data in various application areas is still low. It should not be overlooked that the coverage of big data applications is still not extensive. The transformation application of big data technology needs to be strengthened. Presently, China's industry-university-research collaborative innovation of big data industry is still in the stage of beginning. There are some unfavorable phenomena now. For example, the conversion rate of scientific and technological achievements is low. Competitive innovative leading enterprises and technologybased small and medium-size enterprises(SMEs) are lacking. It could be found that some collaborative innovation participants fail to achieve target demand and some collaborative innovation centers are in an awkward situation. Besides, the talent of the big data industry is in a state of shortage. According to the statistics of the China Business Federation Data Analysis Professional Committee, 14 million basic big data analytical talents will be needed in the near future.

Facing these practical problems, this paper focuses on the industry-university-research collaborative innovation of the big data industry. It analyzes the division of responsibilities between enterprises, universities and research institutes, and the collaborative innovation cooperation model of industry. Looking for effective methods to achieve the organic integration of big data and industry-university-research collaborative innovation of big data industry to promote China's big data technology innovation and progress is one of the main goals of this paper.

\section{THE MAIN ENTITIES AND RESPONSIBILITY OF INDUSTRY-UNIVERSITY-RESEARCH COLLABORATIVE INNOVATION OF BIG DATA INDUSTRY}

The main entities of industry-university-research collaborative innovation of big data industry include government, universities, research institutions, enterprises and intermediary service agencies, etc [1]. The purposes of the cooperation of these different entities are not the same. For government departments, they want to improve management capabilities through big data, reduce administrative costs, and provide environmental support for the transformation of scientific and technological achievements. For universities and research institutions, they hope to engage in basic and applied research in many fields of big data. For companies, they hope to discover new markets and develop new products by using big data analysis. And for intermediary institutions, they want to maximize their benefits by providing consulting services. Industry-university-research collaborative innovation can mobilize the enthusiasm of all innovative entities. By making full use of the unique advantages and resources of each innovation entities, they form a perfect innovation mechanism and a harmonious innovation atmosphere(see Fig. 1). This can generate a powerful big data industry innovation effect and economic impetus. 


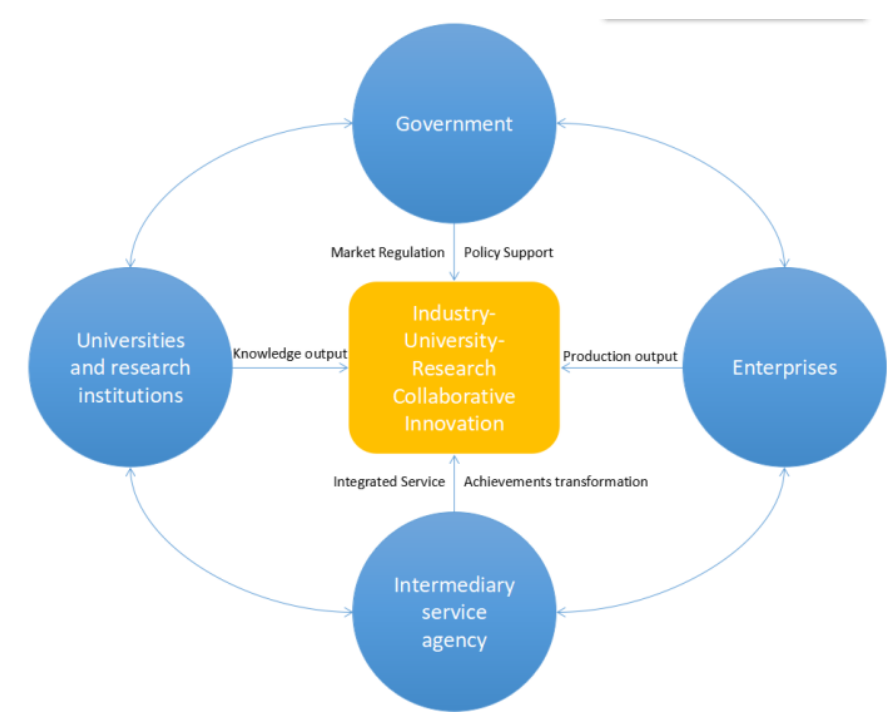

Fig. 1. Relationship Between Entities

\section{A. Government entities}

Government entities include relevant state departments, provincial governments, municipal governments, relevant regional leaders and management departments. Government departments at all levels can provide relevant industrial policies for big data enterprise entities. Moreover, relevant science and technology incentive policies for universities and scientific research institutions could be provided by this entity. Policies which support for collaborative innovation activities of industry-university-research in big data industry could also be provided. And the government may also adopt corresponding control measures according to different market demand.

\section{B. University entities}

Universities and research institutions are big data technologies and knowledge providers in various industryuniversity-research collaborative innovation activities. All kinds of universities and scientific research institutions are mainly responsible for exploring the frontier technology of big data, cultivating big data talents for the society, and carrying out all-round cooperation in large-scale production. At the same time, universities and research institutes maintain good communication with various intermediary service agencies. University entities would make full use of the resources of various intermediary service organizations, and find corresponding financial support, consulting and evaluating services for various big data technology innovation projects, business plans and technological achievements transformation and application.

\section{Business entities}

The enterprise is the transformer of the market demand and results of the industry-university-research collaborative innovation activities. Enterprise entities include big data infrastructure, big data platform, GIS platform, big data processing, data visualization, big data marketing, industry big data and so on. Under the leadership and coordination of government departments, enterprises should maintain close cooperative relations with relevant universities and research institutions, and carry out all-round cooperation in production, education and research with major disciplines and majors in big data. At the same time, this entity communicates and cooperates with relevant intermediary service organizations to evaluate and analyze all aspects of the big data industryuniversity research collaboration innovation cooperation project. Accurate assessment and analysis can provide corresponding investment and guarantee for each cooperation project, ensuring the smooth implementation of collaborative research and innovation cooperation projects.

\section{Intermediary service agency}

Intermediary service agencies are escorts for smooth development of various big data cooperation projects Intermediary services agencies include financial services companies, risk analysis and investment companies, information consulting and evaluation companies, and various industry associations. The intermediary service agencies are mainly responsible for providing risk analysis and evaluation, financial support investment, policy consulting analysis, innovation and entrepreneurship project planning, legal consultation and assistance to various industry, university and research innovation cooperation projects of universities, scientific research institutions and enterprises.

\section{COOPERATION MODEL OF INDUSTRY-UNIVERSITY- RESEARCH IN BIG DATA INDUSTRY}

\section{A. Project cooperation model}

The model of cooperation with big data projects is a traditional mode of cooperation. The main features of that are enterprises, universities, and research institutes using specific big data projects as a link, sign cooperation agreements and establish cooperative relationships. Once the project is completed, this cooperation relation would be dissolved. This cooperation model mainly consists of three specific formstechnology transfer mode, project commission mode, and joint R\&D mode.

\section{1) Technology transfer mode}

The technology transfer mode makes full use of the research results of the big data industry that have been developed by universities and research institutions to realize the transfer of new knowledge and new technologies to enterprises and industries. The transaction cost of the technology transfer form is pretty low. The contractual targets of the two parties are clear and the responsibilities, rights and interests of both parties are clear. Although there are also performance risks, but in the early stage, preventive measures can be taken to reduce the risk. Therefore, this mode is generally welcomed.

\section{2) Project commission mode}

Project entrustment is a kind of technical and economic activity that the entrusting party (generally a company) entrusts the project that needs to be completed to the trustee (including the laboratory of a university, research institute or related enterprise). The way of cooperation is that the company proposes the demand for big data projects and provides funds. The universities and research institutes are responsible for project research and development, and the property rights belong to the enterprise. 


\section{3) Joint $R \& D$ mode}

The joint research and development form can fully mobilize the power of industry, academia and research to focus on specific technology projects in the big data industry. This mode enables companies to effectively use the research resources of academic institutions and make the research of academic institutions more explicit.

\section{B. Platform cooperation model}

Establishing a big data platform cooperation model is a relatively close cooperation model. The characteristics of this model are that enterprises, universities, and research institutes jointly invest resources to establish a platform, and take the platform as the main body for scientific research. The specific forms of this model include the Co-constructed research base model and derivative enterprise model.

\section{1) Co-constructed research base model}

The Co-constructed research base mode is a relatively close form of cooperation between industry, academia and research. It is invested by enterprises, scientific research institutions and universities to establish a large proportion of funds, manpower or equipment to jointly establish a research base for big data joint research and development institutions, joint laboratories and engineering technology centers.

\section{2) Derivative enterprise model}

Innovative companies derived from universities and research institutions are an important type of technology transfer and cooperation in industry-university- research. University-derived enterprises hatch in the maternal body of the university, serve as a bridge for university technology transfer, and give back to the university in the process of continuous development and growth of the enterprise, support the basic research of the university, and promote the discipline construction and talent cultivation of the university.

\section{Technology alliance cooperation model}

The Industrial Technology Alliance cooperation model aims to build a corresponding industrial technology alliance with enterprises and scientific research institutions around the creation of innovative technologies and common technology research. Such alliances can help the participating entities to concentrate their strengths on industrial technology innovation, share risks and share benefits. The specific modes include the contract industry technology alliance method and the entity industry technology alliance method.

\section{1) Contract industry technology alliance method}

Contractual industrial technology alliance refers to the establishment of strategic and technological alliances on the basis of equality, voluntary and mutual benefit among relevant enterprises, universities and scientific research institutions in the industry, and cooperation and research and development under the contractual norms. This kind of approach is an organizational partnership concluded by agreement. This kind of agreement is different from the traditional enterprise organization established by relying on assets as a link. It is a semi-integration between enterprises and markets. Intermediate organization status

\section{2) The entity industry technology alliance method}

The entity industrial technology alliance refers to the sharing of risks and sharing of income by a number of enterprises, universities, and research institutes in the industry alliance, establishing an independent group legal person or establishing a new company. Every partner will invest in the legal entity with their respective superior resources.

\section{CONCLUSION AND SugGeSTION}

The aim of industry-university-research collaborative innovation of big data industry is to achieve the collaboration and the win-win for all participants. According to the previous findings, this paper proposes four suggestions for further improving the efficiency and effectiveness of the industryuniversity-research cooperation in big data industry.

First, the government should create a good external environment. The main entities of collaborative innovation are the industry, the university and the research institution. What the government needs to do is to take appropriate and corrective measures to control in terms of planning, policy, legislation and macroeconomic regulation. In the beginning, according to the actual situation in the region of economy, science and technology and social development, special development plans for industry-university-research collaborative innovation need to be developed to guide and promote the development of industry-university-research cooperation in the region. And relevant laws, regulations and policy documents need to be formulated by governments. These documents can regulate and constrain the behavior of the participating entities, clarify the ownership of the cooperative results and the proportion of income distribution, and protect the interests of all parties involved. Moreover, increasing $\mathrm{R} \& \mathrm{D}$ investment is one of the government's responsibilities. Providing various policy concessions and financial support, and improving the supporting service policies such as the information service platform could enable the government to fully exert its regulatory role.

Second, the three parties of industry-university-research need to cultivate and introduce innovative talents and conduct tracking management for them. According to the development plan and research prospects of the three industries of the big data industry, at present, all entities should first analyze the strategic needs of the talents and the talent team. Next potential employees or innovative talents need to be cultivated and introduced. It is a good strategic method to give each other generous treatment and good research conditions and academic atmosphere. What cannot be ignored is to track and manage the research activities of talents to ensure that researchers could complete the necessary scientific research tasks.

Third, raise research funding through multiple channels to improve the use of funds. Big data industry is a high-input industry, so the industry-university-research cooperation in big data industry should be based on the situation of abundant human, material and financial resources. Based on the existing research facilities and personnel input, it is necessary to raise research funds through various channels, including government investment, self-funding by the participating entities, and funding by technology demanders. Diversifying 
social funding sources and ensuring continuity can ensure the smooth progress of research activities.

Finally, establish an incentive mechanism for scientific research results and effectively play its guiding role. Reasonable incentive can stimulate the enthusiasm of researchers and enable them to devote themselves to scientific research activities. The incentive mechanism of scientific research results has a clear guiding effect on scientific research activities. Therefore, the three entities and research teams of the industry-university-research of the big data industry should reasonably formulate research incentive policies, increase incentives for high-quality and innovative results, and encourage researchers to challenge higher-level innovation activities.

\section{REFERENCES}

[1] Chen Jian-guo, Liu Yu-hua, Chen Yi-chang, Huang Rui-xing, Wu Xian, Research on the Relationship and Responsibility of the Innovation Cooperation Main Body of Industry-University-Research in Big Data Environment[J]. Journal of Shenyang Institute of Engineering, 2017, $13(2): 248-252$.

[2] Fiaz M. An empirical study of university-industry R\&D collaboration in China: Implications for technology in society[J]. Technology in Society, 2013, 35(3): 191-202.

[3] Schwartz M, Peglow F, Fritsch M, et al. What drives innovation output from subsidized R\&D cooperation? - Project-level evidence from Germany[J]. Technovation, 2012, 32(6): 358-369.

[4] Ozcan S, Islam N. Collaborative networks and technology clusters-The case of nanowire[J]. Technological Forecasting and Social Change, 2014 82: 115-131.

[5] OECD. Exploring data-driven innovation as a new source of growth: Mapping the policy issues raised by " big data" [EB /OL] . [2013 06 - 18] .http:/ /dx.doi.org /10.1787/5k47zw3fcp43-en.

[6] OECD.Data-driven innovation: Big data for growth and well-being [ EB /OL ] . [ $2015-10-01$ ] .http:/ /dx.doi.org $/ 10.1787 / 9789264229358-$ en.

[7] Lee S, Park G, Yoon B, et al. Open innovation in SMEs - An intermediated network model[J]. Research policy, 2010, 39(2): 290-300.

[8] Oke A, Kach A. Linking sourcing and collaborative strategies to financial performance: The role of operational innovation[J]. Journal of Purchasing and Supply Management, 2012, 18(1): 46-59

[9] Trigo A, Vence X. Scope and patterns of innovation cooperation in Spanish service enterprises[J]. Research Policy, 2012, 41(3): 602-613.

[10] Bruneel J, d'Este P, Salter A. Investigating the factors that diminish the barriers to university-industry collaboration[J]. Research policy, 2010, 39(7): 858-868 